\title{
Prediction of heat and fluid flow in microchannel condensation
}

\author{
Anil Basaran ${ }^{1}$, Ali Cemal Benim ${ }^{1, *}$, and Ali Yurddas ${ }^{2}$
}

${ }^{1}$ Center of Flow Simulation (CFS), Department of Mechanical and Process Engineering, Düsseldorf University of Applied Sciences, Münsterstr. 156, D-40476 Düsseldorf, Germany

${ }^{2}$ Manisa Celal Bayar University, Faculty of Engineering, Department of Mechanical Engineering, 45140, Yunusemre, Manisa, Turkey.

\begin{abstract}
The condensing flow inside the microchannel has gained importance as the microchannel heat exchangers are widely used in the industry. In this study, a number of numerical simulations on condensing flow inside the microchannel were conducted to investigate heat transfer characteristic. Circular microchannel geometries with the various diameters were considered. The Volume of Fluid model was used to model twophase flow. The phase change at the saturation temperature was modeled by the Lee model. In the considered geometries, different from the conventional channels, surface tension forces can be important compared to other forces. Therefore, surface tension was considered in the simulations. Constant wall heat flux and constant saturation temperature were applied as simulation conditions, similar to actual operating conditions. The predictions were validated by comparisons with the experimental results that exist in the literature. A satisfactory agreement of the present predictions with the experimental data was observed.
\end{abstract}

\section{Introduction}

Heat transfer occupies a central role in a wide range of engineering applications pertaining to energy conversion, encompassing power generation [1], heating/cooling as well as energy recovery [2]. Thus, heat transfer processes have been the subject of intensive investigations over many years $[3,4]$. Forced convection heat exchangers are the widely used heat transfer devices. Here, microchannel heat exchangers (MCHE) have been recently becoming an attractive heat exchanger designs due to their outstanding advantages for certain applications.

The most noticeable benefits of the MCHEs are the compact design and improved total heat transfer coefficient $[5,6]$. The MCHEs are becoming widespread designs in industrial applications like refrigeration, electronic cooling, air-conditioning, heat pump, HVAC, etc, recently. In these applications, the system is designed in a way that the working fluid, generally refrigerant, undergoes a phase change in condenser/evaporator. Achieving a high heat transfer rate in small volumes is one of the main challenges in heat exchanger design, in general. The MCHEs are most promising design to meet this challenge due to their advantages. On the other hand, a different flow regime and heat transfer mechanism occur in the microchannel than in the conventional channels with the reduction of the hydraulic diameter [7-9]. Hence, determination of fluid flow and heat transfer characteristics during condensation of refrigerant in microchannel gain importance in terms of a condenser performance. In the literature, some numerical studies have been conducted to understand the thermal characteristics of condensation inside microchannels.

Da Riva and Del Col [10] simulated the condensation of R134a inside circular cross-sectional $1 \mathrm{~mm}$ inner diameter mini-channel for high $\left(\mathrm{G}=800 \mathrm{~kg} / \mathrm{m}^{2} \mathrm{~s}\right)$ and low $\left(\mathrm{G}=100 \mathrm{~kg} / \mathrm{m}^{2} \mathrm{~s}\right)$ mass fluxes. In their work, they took into account the effects of the interfacial shear stress, gravity and surface tension for horizontal tube orientation. They conducted the same simulations for vertical downflow with normal gravity as a next step. The simulations with the non-gravity effect were also performed. Similarly, Da Riva and Del Col [11] proposed numerical simulation of laminar liquid film condensation in a horizontal circular mini-channel with an internal diameter of $1 \mathrm{~mm}$. A threedimensional simulation laminar fluid film condensation of R134a inside the mini-channel was conducted using the Volume of Fluid (VOF) method by authors. They run the simulation with and without taking into account surface tension to explore the effect of surface tension under their simulation conditions.

Ganapathy et al. [12] proposed the VOF based numerical model for the simulation of condensation fluid flow characteristics and heat transfer in a single microchannel. They performed the two-dimensional transient simulation for condensation of R134a inside a $100 \mu \mathrm{m}$ microchannel. In their simulations, the vapor mass flux at the channel inlet ranged between 245 and 615 $\mathrm{kg} / \mathrm{m}^{2} \mathrm{~s}$, heat flux ranging from 200 to $800 \mathrm{~kW} / \mathrm{m}^{2}$.

Bortolin et al. [13] performed steady-state numerical simulations of condensation of R134a inside a $1 \mathrm{~mm}$ square mini-channel. In the simulations, the VOF

\footnotetext{
* Corresponding author: alicemal@prof-benim.com
} 
approach was employed to track the vapor-liquid interface during condensation. The simulation was conducted at mass fluxes of $400 \mathrm{~kg} / \mathrm{m}^{2} \mathrm{~s}$ and $800 \mathrm{~kg} / \mathrm{m}^{2} \mathrm{~s}$ and a uniform wall temperature was maintained as a boundary condition. The vapor core and liquid film were treated as turbulent in the numerical model for both mass fluxes. To model turbulence through both liquid and vapor phases, the authors used a low-Re version of the SST k- $\omega$ model. The authors concluded that the gravity effect has a minor effect in the square mini-channel and the heat transfer mechanism was dominated by shear stress and surface tension at considered mass flux.

Another VOF based numerical simulation was conducted by Chen et al. [14]. They simulated, numerically, the condensation flow of refrigerant FC-72 in a rectangular microchannel with a 1-mm hydraulic diameter. Turbulence was modelled by the realizable k- $\varepsilon$ model. It follows from their simulations that decrement of wall cooling heat flux or increment of flow mass flux increase the vapor column length.

$\mathrm{Wu}$ and $\mathrm{Li}$ [15] proposed a transient numerical model for the condensation heat transfer and flow features. They studied the simulation of condensation flow of R32 in a circular with $0.1 \mathrm{~mm}$ diameter. They successively simulated four flow patterns (annular, injection flow, slug flow, and bubbly flow) in a two-dimensional calculation domain. $\mathrm{Wu}$ and $\mathrm{Li}$ [15] conducted another study on transient condensation flow of R32 to investigate interfacial wave behavior and its effect on flow and condensation heat transfer. They run simulations with a two-dimensional axis-symmetrical domain with $5 \mathrm{~mm}$ length. The mechanism for interfacial wave appearance, propagation and growth were screened at 50, 100 and 200 $\mathrm{kg} / \mathrm{m}^{2} \mathrm{~s}$ mass fluxes.

Zhang et al. [16] numerically investigated heat transfer and pressure drop characteristics of condensation for R410A inside horizontal microchannel tubes $\left(D_{h}=\right.$ $0.25,1$, and $2 \mathrm{~mm}$ ) at different saturation temperatures. They mainly focused on the effects of saturation temperature of R410A on heat transfer and pressure drop characteristics. The VOF model was adopted. The SST$\mathrm{k}-\omega$ turbulent model was used for both phases.

Microchannel condenser designs have been gradually getting importance in recent years. Several studies have been carried out to develop the correlations which predict the heat transfer coefficient of the refrigerant flow in the microchannel with high precision. But a predictive tool for fluid flow in the microchannel that is applicable to a wide range of working fluids, mass velocities, pressures, channel geometries, and channel diameters is still deficient in literature. There is no available heat transfer correlation developed especially for both single and twophase flow of isobutane (R600a) in the microchannel with different channel cross sections and diameters. Such an important parameter in terms of heat transfer performance can be determined by means of CFD analysis.

In the present study, steady-state simulations of condensation flow of R600a are performed at mass fluxes ranging from 200 to $600 \mathrm{~kg} / \mathrm{m}^{2} \mathrm{~s}$ inside a single circular microchannel with various diameters. The main purpose of the present study is to determine the heat transfer coefficient inside the microchannel during condensation of R600a. The model considered in the present study is validated against experimental data of condensation of $\mathrm{R} 134 \mathrm{a}$ inside circular microchannel. Then the model is adopted for simulations of R600a condensation.

\section{Numerical Modelling}

\subsection{Simulation conditions}

In the present study, steady-state numerical simulations of condensation flow of R600a are performed at mass fluxes ranging from 200 to $600 \mathrm{~kg} / \mathrm{m}^{2} \mathrm{~s}$ inside a single circular, smooth microchannel. The diameter of microchannel is varied between 200 to $600 \mu \mathrm{m}$, keeping its length constant at $5 \mathrm{~mm}$. In the simulations, condensation flow is investigated at the different inlet thermodynamic vapor qualities ( $\mathrm{x}=0.3,0.50 .7$, and 0.9$)$. Uniform heat flux of 40 $\mathrm{kW} / \mathrm{m}^{2}$ is maintained at the microchannel wall as the thermal boundary condition. No-slip boundary condition applies for the velocities. The condensation simulations of $\mathrm{R} 600 \mathrm{a}$ are performed for a saturation temperature of $40^{\circ} \mathrm{C}$. Thermophysical properties of R600a corresponding to the saturation temperature are given as follows (L: liquid, V: vapor): Density $\left(\mathrm{kg} / \mathrm{m}^{3}\right): 531.2(\mathrm{~L}), 13.7(\mathrm{~V})$; Specific heat $(\mathrm{kJ} / \mathrm{kg} \cdot \mathrm{K}): 2.5349(\mathrm{~L}), 1.921(\mathrm{~V})$; Thermal conductivity (W/mK): 0.084051 (L), 0.018524 (V); Viscosity (Pas): 0.000129 (L), 0.00000791 (V); Prandtl number (-): $3.9024(\mathrm{~L}), 0.82056(\mathrm{~V})$; Surface tension $(\mathrm{N} / \mathrm{m}): 0.0084105$, Saturation pressure $(\mathrm{kPa}): 531.21$.

For the considered cases, the pressure drops along the microchannel lengths were relatively small compared to the system pressure at the saturation temperature. Therefore, thermophysical properties of working fluid were assumed as constant. For assessing the relative roles of the surface tension and gravity, the Bond number based criteria discussed by Li and Wang [17] and Nema et al. [18] are applied, which indicated a subordinate role of the gravity in the present cases. Thus, the gravity is neglected in the present calculations.

It is worth to note that the steady-state simulations do not allow to model possible instabilities, and waves at the interface. Therefore, intermittent flow pattern like wavy, bubbly, slug/plug flows cannot be predicted with steadystate simulations. Thus, the adequacy of the applied steady-state analysis for the considered cases needs to be justified. This is done by means of flow pattern maps.

One of the well-accepted flow pattern maps is the one proposed by Coleman and Garimella [19]. According to this map, the flow regime is expected to be annular flow for the cases considered in the present simulations. Nema et al. [18] proposed a new flow regime transition criterion for micro channels, according to which, the wavy flow regime is not present if the Bond number is lower than a critical value. In the presently considered cases, the Bond number was lower than this critical Bond number [18]. Therefore, the flow pattern across the channel length is expected to be annular flow in the presently considered cases, and a steady-state formulation is applied.

Two separate inlets for vapor and liquid phases were considered at the inlet boundary. The inlet velocities of 
both vapor $\left(U_{V}\right)$ and liquid phases $\left(U_{L}\right)$ were calculated depending on mass flux $(G)$ and quality $(x)$ as below

$$
\begin{gathered}
U_{L}=\frac{(1-x) G D^{2}}{\rho_{L}\left(D^{2}-D_{V}^{2}\right)} \\
U_{V}=\frac{x G D^{2}}{\rho_{L} D_{V}^{2}}
\end{gathered}
$$

where $D$ and $D_{V}$ are diameters of microchannel and vapor core, respectively, $\rho$ denoting density. Subscripts $L$ and $V$ stay for "liquid" and "vapor". Liquid and vapor phases are assumed as incompressible.

The solution domain is discretized by quadrilateral volumes. The mesh was refined locally near the wall. A grid independence study was performed for the case with a mass flux of $400 \mathrm{~kg} / \mathrm{m}^{2} \mathrm{~s}$. Five meshes from coarse (12750 volumes) to fine (156000 volumes) were tested. After 51000 cells, the change in the average wall temperature and heat transfer coefficient were smaller than $0.02 \%$ and $2.11 \%$, respectively. Therefore, the mesh with 51000 cells was adopted for further simulations.

\subsection{The Volume of Fluid (VOF) model}

Among the available interface capturing methods to simulate two-phase flow, the Volume of Fluid (VOF) [20] method is one of the popular methods. The main idea of the VOF method is the definition of a scalar volume fraction $\left(\alpha_{i}\right)$ representing the portion of the volume of the computational cell filled with the particular phase $i$ and to transport these quantities with velocity field.

In the VOF model, the momentum equations of the phases interact by the interfacial forces containing surface tension. These are modeled after Brackbill et al. [21] also taking interface curvature into account.

In the condensation process, phase change between the liquid and vapor phases takes place at the interface by mass transfer from vapor to liquid related to the release of latent heat. The mass transfer model proposed by Lee [22] is employed in the current study to simulate mass transfer at the interface during condensation. For the model constant $r$, values between $5 \times 10^{5}-4 \times 10^{6}$ are adopted for $\mathrm{r}$. For these values, the difference between the saturation and computed interface temperatures were smaller than $1 \mathrm{~K}$.

\subsection{Solution methods}

The simulations are performed using the finite volume based CFD code ANSYS Fluent 19.2 [23]. As stated earlier, the VOF model is used to simulate multi-phase flow in steady-state condensation. In recent years highresolution procedures such as the Large Eddy Simulation (LES) are increasingly being used to model turbulence [24-26]. However, in the present work a Reynolds Averaged Numerical Simulation (RANS) [27] approach is applied, using the Shear Stress Transport (SST) k- $\omega$ model [28] as turbulence model, which was successfully used in many different applications before [29]. The SIMPLE scheme is used for pressure-velocity coupling. The MUSCL scheme is applied to discretize the transport equations. The PRESTO scheme is employed for pressure while modified HRIC is used for the volume fraction.

\section{Results}

\subsection{Verification of the model}

To validate the presently proposed numerical model, the simulation results are compared with the experimental data available in literature. Within this scope, the experimental results of Shin and Kim [30] are taken as the basis, and the predicted heat transfer coefficients are compared with the measured values by Shin and Kim [30]. The condensation of R134a inside a horizontal microchannel with diameter $0.493 \mathrm{~mm}$ is simulated. The comparison of the simulation results with the experimental data is provided in Fig. 1 for different values of the mass flux. It can be observed in Fig. 1 that predicted the heat transfer coefficients are in a fairly good agreement with the measurements for all mass fluxes. Although the deviation between simulation and experimental results increase with increasing vapor quality, the maximum relative deviation remains lower than $26 \%$. At this stage, it is also worth to note that in the experiments of Shin and Kim [30], the uncertainty in the measured heat transfer rate was reported to be $\pm 12.9 \%$.

\subsection{Heat transfer Coefficient}

Reliable information is lacking for certain refrigerants, especially for R600a, although this refrigerant has an important potential in the design of microchannel condensers. Thus, the present work aims to provide a contribution for the determination of the heat transfer coefficient for the condensation of R600a in microchannels, by means of numerical simulations. Condensation of R600a inside a single circular microchannel is investigated. The predicted heat transfer coefficients for the condensing flow of R600a in microchannel, for $400 \mathrm{~kg} / \mathrm{m}^{2}$ s, are provided in Fig. 2, for different diameters of the microchannel. It can clearly be

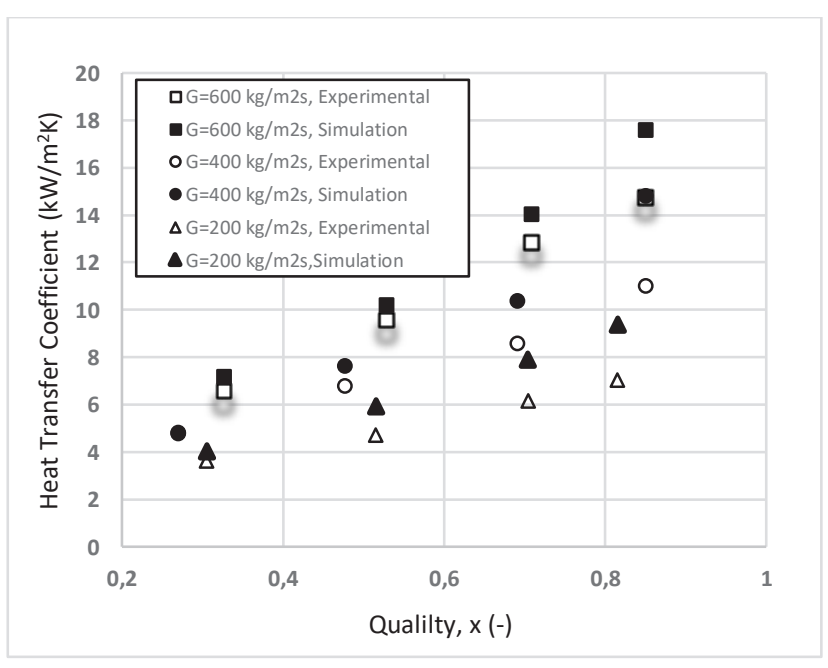

Fig. 1. Comparison of predicted and experimental [30] heat transfer coefficients for condensation of R134a in microchannel. 
seen in the figure that a decrease in the diameter results in increasing heat transfer coefficients. Additionally, the heat transfer coefficients increase in parallel with increasing inlet vapor qualities for all investigated diameters. These results are consistent with experimental studies existing in the literature. According to Fig. 2, the impact of diameter on the heat transfer coefficient is comparably low at low inlet vapor qualities. On the other hand, the increment of heat transfer coefficients related to diameter becomes apparent at higher inlet vapor qualities. Heat transfer coefficient increments for $\mathrm{D}=0.2 \mathrm{~mm}$ is larger than the increments in $\mathrm{D}=0.4$ and $\mathrm{D}=0.6 \mathrm{~mm}$, while the values for the latter two are not much different for all quality values.

The variation of the predicted heat transfer coefficient as function of mass flux is presented in Fig. 3. It can be observed in Fig. 3 that the heat transfer coefficient increases with increasing mass flux. There is a nearly proportional increment in the heat transfer coefficient with the mass flux. The rate of change of the heat transfer coefficient with vapor quality is nearly constant and the same for all considered values of the mass flux, resulting in nearly linear curves that are nearly parallel to each other. As a summary, it can be stated that the mass flux has an enhancing effect on the heat transfer coefficient for condensation flow of R600a inside the microchannel, where the heat transfer coefficient also increases with the vapor quality, which was also observed in Fig. 2.

In Fig. 4, the predicted heat transfer coefficients at the value $x=0.5$ of the inlet vapor quality are illustrated for the investigated values of the mass flux and microchannel diameter. According to Fig. 4, when the diameter is varied from 0.6 to $0.4 \mathrm{~mm}$, the heat transfer coefficients show small variations for all simulated mass flux values.

On the other hand, when the diameter is changed to $0.2 \mathrm{~mm}$, the heat transfer coefficients show higher alterations. When the mass flux values are compared, it can be observed that the heat transfer coefficients experience a rather linear increment for the considered diameters with the change of mass flux.

\section{Conclusions}

A numerical simulation of the condensing flow of R600a inside a single circular microchannel is presented. It is aimed to investigate the effect of hydraulic diameter, mass flux and inlet vapor quality on the heat transfer coefficient, motivated by the fact that there is lack of information on R600a condensation in microchannels. The proposed numerical model is verified by the available experimental data on the condensation of R134a in microchannel.

It is observed that the heat transfer coefficient increases with decreasing hydraulic diameter and increasing mass flux, consistent with the general findings in the literature for different working fluids.

Further, the increment in inlet vapor quality is observed to result in higher heat transfer coefficient for all simulated diameter and mass flux values. The main reasons for this situation are the increasing of vapor core diameter and decreasing liquid film thickness inside microchannel with the increment of inlet vapor quality.

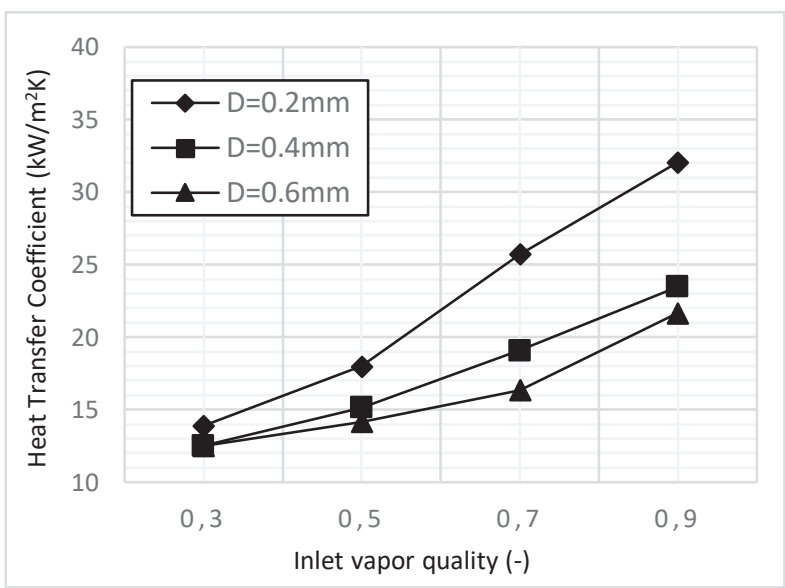

Fig. 2. Variation of predicted heat transfer coefficients for the condensing flow of R600a in microchannel for $\mathrm{G}=400 \mathrm{~kg} / \mathrm{m}^{2} \mathrm{~s}$.

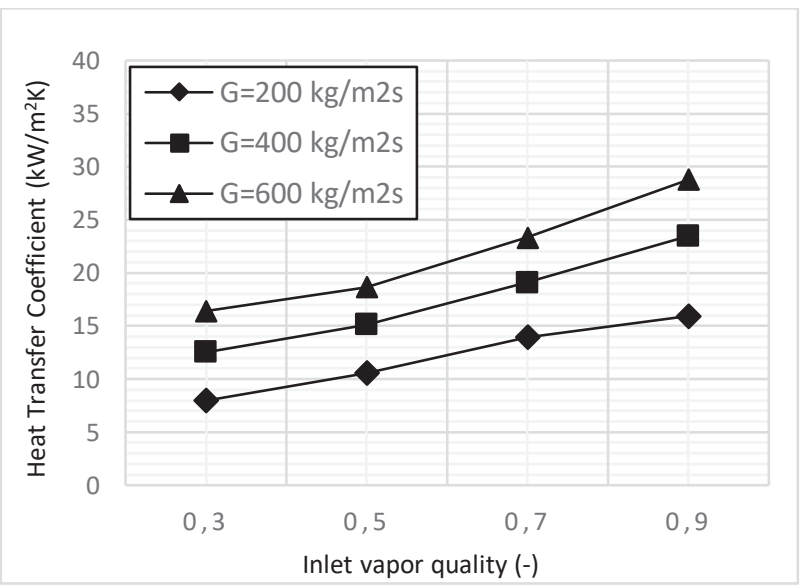

Fig. 3. The variation of condensation heat transfer coefficients of R600a inside $\mathrm{D}=0.4 \mathrm{~mm}$ for different mass fluxes.

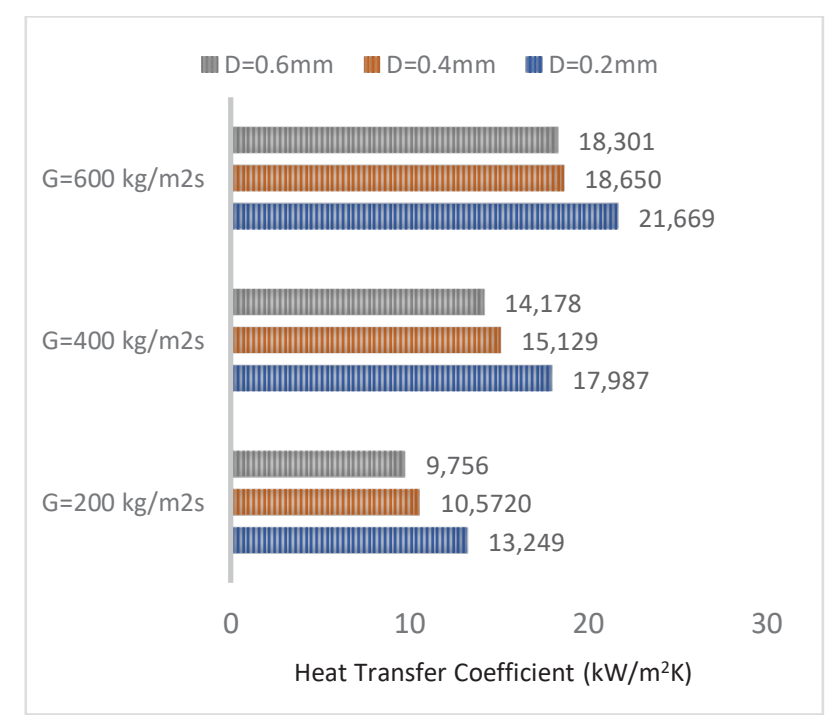

Fig. 4. Predicted heat transfer coefficients of condensation of $\mathrm{R} 600 \mathrm{a}$ in microchannel for $\mathrm{xin}=0.5$.

Anıl Başaran thanks TUBITAK for the awarded grant for a research fellowship at the CFS, Düsseldorf University of Applied Sciences, Düsseldorf, Germany. 


\section{References}

1. A.C. Benim, M. Geiger, S. Doehler, M. Schoenenberger, H. Roemer, "Modelling the flow in the exhaust hood of steam turbines under consideration of turbine-exhaust hood interaction", in: Proceed. 1st European Conf. Turbomachinery Fluid Dynamic and Thermodynamic Aspects: Computational. Methods, Erlangen, Germany, March 1-3, 1995, Book Series: VDI Ber., Vol.1185, pp.343357 (VDI Verlag, Duesseldorf, 1995)

2. D.G. Ebling, A. Krumm, B. Pfeiffelmann, J. Gottschald, J. Bruchmann, A.C. Benim, M. Adam, R. Labs, R.R. Herbertz, A. Stunz, "Development of a system for thermoelectric heat recovery from stationary industrial processes", Journal of Electronic Materials, 45(7), pp.3433-3439 (2016)

3. A.C. Benim, "A finite element solution of radiative heat transfer in participating media utilizing the moment method", Computer Methods in Applied Mechanics and Engineering, 67(1), pp.1-14 (1988)

4. A.C. Benim, M. Cagan, D. Gunes, "Computational analysis of transient heat transfer in turbulent pipe flow", International Journal of Thermal Sciences, 43(8), pp.725-732 (2004)

5. S.G. Kandlikar, "A roadmap for implementing minichannels in refrigeration and air-conditioning systems - Current status and future directions", Heat Transfer Engineering, 28, pp.973-85 (2007)

6. K. Roth, D. Westphalen, J. Dieckmann, S. Hamilton, W. Goetzler, "Energy consumption characteristics of commercial building HVAC systems", Vol 3, Energy savings potential, NTIS Rep. PB2002-107657 (2002)

7. S.G. Kandlikar, S. Colin, Y. Peles, S. Garimella, R.F. Pease, J.J. Brandner, et al., "Heat Transfer in Microchannels-2012 Status and Research Needs", Journal of Heat Transfer, 135, pp.91001 (2013)

8. F.P. Incorpera, D.D. Dewitt, T.L. Bergman, A.S. Lavine, Principles of Heat and Mass Transfer, $7^{\text {th }}$ Ed. (Wiley, Singapore, 2013)

9. S.M. Ghiaasiaan, Two-Phase Flow, Boiling, and Condensation, $2^{\text {nd }}$ Ed. (Cambridge University Press, Cambridge, 2017)

10. E.Da Riva, D.Del Col, "Effect of gravity during condensation of R134a in a circular minichannel: VOF simulation of annular condensation", Microgravity Sci. Techn., 23, pp.87-97 (2011)

11. E. Da Riva, D. Del Col, "Numerical Simulation of Laminar Liquid Film Condensation in a Horizontal Circular Minichannel", Journal of Heat Transfer, 134, pp.51019 (2012)

12. H. Ganapathy, A. Shooshtari, K. Choo, S. Dessiatoun, M. Alshehhi, M. Ohadi, "Volume of fluid-based numerical modeling of condensation heat transfer and fluid flow characteristics in microchannels", Int. J. Heat and Mass Transfer, 65, pp.62-72 (2013)

13. S. Bortolin, E. Da Riva, D. Del Col, "Condensation in a square minichannel: Application of the VOF method", Heat Transfer Eng., 35, pp.193-203 (2014)
14. S. Chen, Z. Yang, Y. Duan, Y. Chen, D. Wu, "Simulation of condensation flow in a rectangular microchannel", Chemical Eng. and Processing: Process Intensification, 76, pp.60-9 (2014)

15. C. Wu, J. Li, "Numerical simulation of flow patterns and the effect on heat flux during R32 condensation in microtube", International Journal of Heat and Mass Transfer, 121, pp.265-74 (2018)

16. J. Zhang, W. Li, W.J. Minkowycz, "Numerical simulation of condensation for R410A at varying saturation temperatures in mini/micro tubes", Numerical Heat Transfer; A 69, pp.464-78 (2016)

17. J.M. Li, B.X. Wang, "Size effect on two-phase regime for condensation in micro/mini tubes", Heat Transfer - Asian Research, 32, pp.65-71 (2003)

18. G. Nema, S. Garimella, B.M. Fronk, "Flow regime transitions during condensation in microchannels", International J. Refrigeration, 40, pp.227-40 (2014)

19. J.W. Coleman, S. Garimella, "Two-phase flow regimes in round, square and rectangular tubes during condensation of refrigerant R 134a", International Journal of Refrigeration, 26, pp.117-28 (2003)

20. C.W. Hirt, B.D. Nichols, "Volume of fluid ( VOF ) method for the dynamics of free boundaries", J. Computational Physics, 39, pp.201-25 (1981)

21. J.U. Brackbill, D.B. Kothe, C. Zemach, "A continuum method for modeling surface tension", J. Computational Physics, 100, pp.335-54 (1992)

22. W.H. Lee, "A pressure iteration scheme for twophase flow modeling", Technical Report, Los Alamos Scientific Laboatory, University of California, New Mexico (1979)

23. ANSYS® FLUENT 19.2, www.ansys.com

24. P. Sagaut, Large Eddy Simulation for Incompressible Flows - An Introduction (Springer, Berlin, 2006)

25. E. Garnier, N. Adams, P. Sagaut, Large Eddy Simulation for Compressible Flows (Springer, Berlin, 2009)

26. A.C. Benim, M.P. Escudier, A. Nahavandi, A.K. Nickson, K.J. Syed, F. Joos, "Experimental and numerical investigation of isothermal flow in an idealized swirl combustor", International Journal of Numerical Methods for Heat \& Fluid Flow, 20(3), pp.348-370 (2010)

27. P.A. Durbin, B.A. Pettersson Reif, Statistical Theoy and Modeling for Turbulent Flows, $2^{\text {nd }}$ Ed. (Wiley, Hoboken, NJ, USA, 2011)

28. F.R. Menter, "Two-equation eddy-viscosity turbulence models for engineering applications", AIAA Journal, 32 (1994)

29. A.C. Benim, K. Ozkan, M. Cagan, D. Gunes, "Computational investigation of turbulent jet impinging onto rotating disk", Int. J. Num. Methods for Heat \& Fluid Flow, 17(3), pp.284-301 (2007)

30. J.S. Shin, M.H. Kim, "An experimental study of flow condensation heat transfer inside circular and rectangular mini-channels", Heat Transfer Engineering, 26 (3), pp.36-44 (2005) 